\title{
FORMULATION AND QBD BASED OPTIMIZATION OF METHOTREXATE-LOADED SOLID LIPID NANOPARTICLES FOR AN EFFECTIVE ANTI-CANCER TREATMENT
}

\section{CHAITALI SURVE ${ }^{1 \# \$}$, RUCHI SINGH ${ }^{2 \$}$, ANANYA BANERJEE ${ }^{3}$, SRINIVAS PATNAIK ${ }^{3 *}$, SUPRIYA SHIDHAYE ${ }^{{ }^{*}}$}

1Department of Pharmaceutics, Vivekanand Education Society's College of Pharmacy, Mumbai 400074, India, ${ }^{2}$ Department of Quality Assurance, Vivekanand Education Society's College of Pharmacy, Mumbai, India, 3School of Biotechnology, KIIT University, Bhubaneswar, India, \#Chaitali Surve is a registered research scholar at the Faculty of Pharmacy, Pacific Academy of Higher Education and Research University, Udaipur, Rajasthan, \$Chaitali Surve and Ruchi Singh are co-first authors

Email: s.shidhaye@ves.ac.in

Received: 10 Jun 2021, Revised and Accepted: 31 Jul 2021

ABSTRACT

Objective: In the current study, the Quality by Design method was utilized for the formulation of solid lipid nanoparticles of Methotrexate (MTX SLNs).

Methods: MTX SLNs formulated by melt emulsification method were studied for the effect of independent variables viz. concentration of lipid and surfactants on quality attributes viz. particle size, polydispersity index, and entrapment efficiency of SLNs using $3^{2}$ factorial design.

Results: The optimal formulation was spherical, had a particle size of $147.6 \pm 4.1 \mathrm{~nm}$ (z-average), a polydispersity index of $0.296 \pm 0.058$, a zeta potential of $-19 \pm 0.98 \mathrm{mV}$, encapsulation efficiency of $98.7 \pm 1.55 \%$, and a cumulative drug release of $95.59 \pm 0.918 \%$ in $5 \mathrm{~h}$.

Conclusion: The in vitro and in vivo studies revealed that SLNs provide a promising oral delivery system to improve the bioavailability of MTX.

Keywords: Oral route, Methotrexate, Solid lipid nanoparticles, Glycerol monostearate, Factorial design

(C) 2021 The Authors. Published by Innovare Academic Sciences Pvt Ltd. This is an open access article under the CC BY license (https://creativecommons.org/licenses/by/4.0/) DOI: https://dx.doi.org/10.22159/ijap.2021v13i5.42373. Journal homepage: https://innovareacademics.in/journals/index.php/ijap

\section{INTRODUCTION}

Methotrexate (N-[4-[[(2, 4-Diamino-6-pteridinyl) methyl] nmethylamino] benzoyl]-L-glutamic acid or 4-Amino-N10-methylpteroyl-L-glutamic acid)(MTX) is used in the management of breast cancer, epidermoid cancers of the head and neck, advanced mycosis fungoides, nonHodgkin's lymphomas, and lung cancer. It inhibits dihydrofolate reductase, thymidylate synthase, and 5-aminoimidazole carboxamide ribotide transformylase [1]. The role of these enzymes is to synthesize thymidylate, purines, methionine, and serine. Although it has relatively low toxicity when compared to other anticancer drugs, it shows various side effects [2]

Methotrexate is taken up by active transport by the cell folate receptor. The resistance in the active uptake of the drug through the receptor is the major cause for its effectiveness to get hampered. In addition to this, the drug is poorly diffused through cell membranes $[2,3]$. Several drug delivery strategies such as liposomes, nanocapsules and nanoparticles, polymer-drug conjugates, and polymeric micelles have been employed to improve the effectiveness of anticancer agents [4-9]. Compared with polymers, solid lipid nanoparticles (SLNs) tend to give controlled drug release, can incorporate lipophilic and hydrophilic drugs, reduced enzymatic degradation, better physical stability, and economic. SLNs are also amenable for large-scale production, targeting potential, solubility enhancement, and improved bioavailability. SLNs can also help in reducing the dose and dose frequency, improving patient compliance, and delaying the onset of resistance [10-12].

In the past few years, more stress has been given to incorporating quality in the product right from the stage of conception by organizations as EMA, USFDA also MHRA. The QbD approach analyses the risk associated with the product by studying the process and product parameters that are critical $[13,14]$. These critical process parameters (CPP) have a huge impact on critical quality attributes (CQA), which can be studied using the Design of the experiment (DOE) [15]. DOE helps in building quality in the product and might make the process cost-effective and less timeconsuming.

The current study aimed at using the QbD approach to develop MTX SLNs with nontoxic nanocarriers for extended and slow drug release with improved stability and oral bioavailability [16]. Optimized MTX-SLNs, by QbD based approach, were prepared using the emulsification, ultrasonication, and low-temperature solidification method. The final product was characterized for particle size, shape, zeta potential, entrapment efficiency, and in vitro release behavior $[17,18]$. MTX SLN formulation was lyophilized by using a suitable cryoprotectant and evaluated for its short-term stability. The dry powder was further characterized using differential scanning calorimetry (DSC), powder X-ray diffraction (PXRD), and Fourier transform infrared (FT-IR) spectroscopy to confirm the physicochemical stability. 3-(4, 5-dimethylthiazol-2-yl)-2,5diphenyl-tetrazolium bromide (MTT) assay was used to assess the in vitro cytotoxicity of SLNs $[19,20]$. Finally, the pharmacokinetic studies were carried out in male Sprague Dawley (SD) rats and the parameters were calculated using the plasma concentration data acquired by liquid chromatography-tandem mass spectroscopy (LCMS-MS) analysis [21]. An increase in the bioavailability of MTX SLNs confirmed the potential of orally delivered MTX SLNs in clinical applications.

\section{MATERIALS AND METHODS}

\section{Materials}

Methotrexate was provided ex-gratis by Cipla Ltd, India, while Gelucire 44/14, Compritol 888 ATO, and Precirol ATO 5 were received from Gattefosse, France. Cremophor EL, Cremophor RH40, and Kolliphor HS 15 were acquired from BASF, Germany, while Glycerol monostearate (GMS) and Stearic acid were procured from S D Fine Chemicals, India. Polyethylene glycol (PEG) 200 and 400 were obtained from Loba Chemie Pvt Ltd, India. Tween 80 was purchased from Sigma-Aldrich. All other materials employed during the studies were of analytical grade and were used as such as obtained.

\section{Solubility study of MTX in different solid lipids}

The active and the waxes were blended in drug: lipid ratios (D: L) of 1:20 as shown in table 1 . The test tube comprising the active and lipid mixtures were individually heated at temperatures $5{ }^{\circ} \mathrm{C}$ beyond lipid melting point utilizing a water bath and blended employing cyclo mixer. The tubes were perceived for homogeneity, miscibility, and clarity after five minutes of continuous heating and mixing [20]. 


\section{Formulation of MTX SLN}

SLNs were formulated by the emulsification and ultra-sonication method [12]. The formulation procedure is comprised of two separates steps. The first part constituted a blend of lipid, drug, and solubilizer, whereas the second part constituted an aqueous surfactant solution. The drug and lipid mixture was solubilized by melting the lipid beyond its melting point $\left(55-60^{\circ} \mathrm{C}\right)$ to get a homogenized mixture. The aqueous component was brought to the same temperature. At the equilibrium temperature, the aqueous phase was combined with the lipid phase then emulsified with the help of a magnetic stirrer. By maintaining the temperature persistent all through, the primary emulsification course was accomplished. Following the primary emulsification process, ultrasonication was carried out employing a probe sonicator (SONICS, VibraCell, VC 505, USA) at a constant temperature [20]. The MTX SLNs were acquired by cooling down final lipidic dispersion at ambient temperature for $15 \mathrm{~min}$.

\section{Preliminary screening of solubilizer, surfactants, and sonication time}

Making the right choice in identifying the CPP ultimately has an effect on CQAs such as size, PDI, and \% entrapment efficiency (\%EE) of prepared SLN. Solubilizers, a combination of surfactants and sonication time was optimized to achieve SLN, which are small, in a narrow range, and have a high drug entrapping capacity. Based on the solubility study, different batches of MTX SLNs were prepared using the selected lipid as revealed in table $2 \mathrm{a}$ by the process defined above employing tween $80(1.5 \% \mathrm{w} / \mathrm{w})$ as surfactant plus 5 min of probe sonication, batch no.1 (table 2a). To select the best solubilizer, batch no. 2-7 (table 2a) were characterized for the size of the particles, PDI, and encapsulation efficiency. Subsequent to the selection and optimization of the final solubilizer; the concentration of lipid, solubilizer and time of sonication were retained persistent. To study the consequence of a combination of surfactants on CQA, MTX SLNs were formulated with tween $80(1.5 \% \mathrm{w} / \mathrm{w})$, a constant surfactant, and varying another surfactant $(1.5 \% \mathrm{w} / \mathrm{w})$ such as Gelucire 44/14, Kolliphor HS 15, Cremophor RH 40, and Cremophor EL, batch no. 8-11 (table 2a). Consequently, the effect of sonication time (Batch no. 12-15) on CQA was established as revealed in table $2 \mathrm{~b}$.

\section{$3^{2}$ factorial design}

Based on preliminary experimental data, $3^{2}$ factorial design was selected for the optimization of MTX SLNs where the effect of three independent variables or CPP viz., Lipid concentration (X1) and surfactant concentration (X2) on CQA (Y1= size, Y2= PDI and $\mathrm{Y} 3=$ $\%$ EE) was determined at three different levels (table 3, 4). GMS, a combination of tween 80: Kolliphor HS 15 (1:1) and Polyethylene glycol 200 were selected as lipid, surfactant, and solubilizer, respectively. Sonication time (10 $\mathrm{min})$ and Polyethylene glycol 200 $(3 \% \mathrm{w} / \mathrm{w})$ were set as fix levels. $3^{2}$ factorial design was analyzed using Design-Expert software (Version 10, Stat-ease. Inc, USA). The best-fitting experimental model was taken statistically based on a comparison of several statistical parameters like p-value and graphically by 3D response surface plot provided by Design-Expert software. The level of significance was considered at a p-value $<0.05$.

Initial experimental results provided insights into adapting $3^{2}$ factorial designs for the further optimization process. For the study, the influence of CPP viz., Lipid concentration (X1) and surfactant concentration (X2) on CQA viz., $\mathrm{Y} 1=$ size, $\mathrm{Y} 2=\mathrm{PDI}$, and $\mathrm{Y} 3=\% \mathrm{EE}$ were found out at three levels (table 3 and 4). GMS, a combination of tween 80: Kolliphor HS 15 (1:1) and Polyethylene glycol 200 were identified as lipid, surfactant, and solubilizer correspondingly. Fixed levels of sonication time $(10 \mathrm{~min})$ and polyethylene glycol $200(3 \% \mathrm{w} / \mathrm{w})$ were set. The polynomial equation was derived using a $3^{2}$ factorial design on a Design-Expert software (Version 10, Stat-ease. Inc, USA). The best-fitting investigational prototype was selected statistically based on a comparative evaluation of numerous statistical considerations like p-value and the 3D response plot given by Design-Expert software. The level of significance was reflected at a p-value $<0.05$.

\section{Data optimization and model validation}

The construction of the design space, ensuring desired product quality, was analyzed by studying the effect of each independent CPP on CQA. Hence, design space was established via $3^{2}$ factorial. The streamlining was performed to lessen the particle size, PDI and improve \%EE. This was achieved by observing the desirability criteria (numerical) plus overlay plot (graphical). The validation of the established model was done using the check-point analysis method. In this method, two confirmation lots viz., V1, and V2 (table 4) were formulated whereby the magnitude of error between observed and predicted values was evaluated.

\section{Characterization of MTX SLNs}

\section{Particle size, polydispersity index, and zeta potential}

The particle size, polydispersity index (PDI), and zeta potential measurements were performed by photon correlation spectroscopy employing Zetasizer (Nano ZS ${ }^{\mathrm{TM}}$; Malvern Instruments, Malvern, UK). Before measuring size, PDI, and zeta potential, double distilled water was used to 10 times dilute the formulation. Particle size and PDI measurements were performed by taking $1 \mathrm{ml}$ of the diluted formulation into polystyrene cuvettes while zeta potential was measured in a disposable folded capillary cell potential at $25^{\circ} \mathrm{C}$. The dynamic light scattering measurements were taken at the working wavelength of $633 \mathrm{~nm}$ and by using a helium-neon laser as a light source at the scattering angle of $90^{\circ}$.

\section{Transmission electron microscopy analysis}

The morphological characteristics of MTX-SLNs were seen underneath transmission electron microscope (TEM; JEM-1400Plus Electron Microscope, Jeol Co, Japan) using an acceleration voltage of $200 \mathrm{kV}$. The freshly prepared MTX SLNs (diluted with water (1:10)) were placed on a carbon-laminated copper lattice. Later, each sample was air-dried before observing under TEM [22].

\section{Determination of total drug content}

A validated HPLC method was used for the determination of the total drug content of MTX-SLNs. An Agilent column C18 $(4.6 \times 200 \mathrm{~mm}, 5$ $\mathrm{mm}$ ) was employed, the mobile phase was a blend of phosphate buffer (pH 7.4): Acetonitrile (75:25) at flow output of $1 \mathrm{ml} / \mathrm{min}$. The ultraviolet-visible detector having a detection wavelength of $306 \mathrm{~nm}$ at $25{ }^{\circ} \mathrm{C}$ was used, and the injection volume was $20 \mu$ l. The method involved adding an appropriate amount of buffer solution ( $\mathrm{pH}$ 7.4) to a fixed quantity of MTX SLNs to produce a final drug concentration equivalent to $10 \mu \mathrm{g} / \mathrm{ml}$. After bath sonication for $30 \mathrm{~min}$ at $60{ }^{\circ} \mathrm{C}$, the extracted drug from the sample was evaluated using HPLC.

\section{Drug encapsulation efficiency (\%EE) determination}

The separation of the unencapsulated drug using a high-speed centrifuge is one of the crucial steps in carrying out encapsulation efficiency studies. A pellet of the prepared nanoparticles was achieved by centrifuging the formulation at $14,000 \mathrm{rpm}$ for $20 \mathrm{~min}$ at normal temperature. The supernatant obtained was investigated for free MTX by UV spectroscopy at $306 \mathrm{~nm}$ wavelength. The EE equation being:

$$
\mathrm{EE}(\%)=\frac{\text { Wtotal }-\mathrm{Ws}}{\text { Wtotal }} * 100 \%
$$

Ws is the quantity of MTX laden into SLNs and Wtotal is the entire MTX quantity in MTX-SLNs.

\section{In vitro release studies}

The studies were carried out using the dialysis bag technique on a freshly prepared MTX-SLNs sample. Free MTX suspension was used as a control. Hydrochloric acid $\left(\mathrm{HCl}, 0.1 \mathrm{~N}\right.$ ) (for the $1^{\text {st }} \mathrm{h}$ ) and buffered solution ( $0.1 \mathrm{mmol}, \mathrm{pH}$ 7.4) (for the remaining $4 \mathrm{~h}$ ) were used as the simulated gastric and intestinal fluid, respectively. The dialysis bags (MW cut off, 8-12 $\mathrm{kDa}$ ) were immersed in doubledistilled water for $24 \mathrm{~h}$ preceding the experiment. The testing was performed by taking $3 \mathrm{ml}$ of free MTX suspension $(0.83 \mathrm{mg} / \mathrm{ml})$ and $3 \mathrm{ml}$ of MTX SLNs $(0.83 \mathrm{mg} / \mathrm{ml})$ suspension into a dialysis bag by clipping the two ends. These bags were later retained in the dissolution fluid $(50 \mathrm{ml})$ under mild agitation $\left(100 \mathrm{rpm}, 37^{\circ} \mathrm{C}\right)$. At regular fixed intervals, samples of the medium $(5 \mathrm{ml})$ were removed and strained over a $0.22 \mu \mathrm{m}$ filter. Sink conditions were maintained by exchanging the same volume of fresh release medium in the vessel. The amount of MTX released into the filtrate was accessed 
using a UV-Visible Spectrophotometer (Cary 60, Agilent, USA) at a detection wavelength of $306 \mathrm{~nm}$. All measurements were carried out in triplicate.

\section{Preparation of MTX-SLN lyophilized powder}

Lyophilization (freeze-drying) is one of the widely used methods to improve the physicochemical stability of the SLNs. The screening of various cryoprotectants like mannitol, lactose, fructose, dextrose was done at different concentrations $(3 \% \mathrm{w} / \mathrm{v}, 5 \% \mathrm{w} / \mathrm{v}$ as well as $7 \% \mathrm{w} / \mathrm{v}$ ). Individually, they were later mixed with $3 \mathrm{ml}$ MTX-SLNs suspension in a vial (capacity: $10 \mathrm{ml}$ ). The solutions were pre-frozen at $-80{ }^{\circ} \mathrm{C}$ nightlong. After transferring the solutions to a freeze dryer, they were dried at $-50{ }^{\circ} \mathrm{C}$ for $24 \mathrm{~h}$ to get MTX SLN freeze-dried powder. Further, the flow properties of the MTX SLN lyophilized powder were improved by adding neusilin $(7 \% \mathrm{w} / \mathrm{v})$.

\section{Solid-state characterization}

\section{Differential scanning calorimetry (DSC)}

MTX, GMS, crude blend (MTX: blank-SLNs-1:1), and MTX-SLNs were deliberated by DSC (DSC-60; Shimadzu Corporation, Tokyo, Japan). In brief, accurately weighed samples $(5 \mathrm{mg}$ ) were wrapped in aluminum pans. The analysis was carried out by heating at a rate of $10{ }^{\circ} \mathrm{C} / \mathrm{min}$ over a range of $25^{\circ} \mathrm{C}-280^{\circ} \mathrm{C}$ under a nitrogen purge (50 ml/min) [23].

\section{Powder X-ray diffraction (PXRD)}

MTX, GMS, crude blend (MTX: blank-SLNs-1:1), and MTX-SLNs were deliberated utilizing an X-Ray diffractometer (X'PERT MPD, Philips, Holland) employing $\mathrm{Cu}$ anode $\left(1.54 \mathrm{~A}^{\circ}\right)$ at $30 \mathrm{~mA}, 40 \mathrm{kV}$. The examination continued uninterruptedly with a step size of $0.017^{\circ}$ over an angular range $(2 \theta)$ of $3^{\circ}-50^{\circ}$ with Xe filled counter rate detector [23].

\section{FT-IR spectroscopy studies}

The FT-IR investigation was accomplished on the previously mentioned samples. An FT-IR spectrometer (Cary 630, Agilent, USA) recorded the FT-IR bands amid $400 \mathrm{~cm}^{-1}-4,000 \mathrm{~cm}^{-1}$ [23].

\section{Cell evaluation}

\section{Cell culture and growth conditions}

The human colon carcinoma cell line (HCT 116) was graciously provided by National Centre for Cell Science (NCCS), Pune, India. Cells were preserved in Dulbecco's modified Eagle's medium (DMEM) complemented with fetal bovine serum (FBS) $(10 \% \mathrm{v} / \mathrm{v})$, penicillin $(100 \mathrm{U} / \mathrm{ml})$, streptomycin $(100 \mu \mathrm{g} / \mathrm{ml})$ and glutamine $(2$ $\mathrm{mmol}$ ) in a moistened environment with $5 \% \mathrm{CO}_{2} / 95 \%$ air at $37^{\circ} \mathrm{C}$.

\section{MTT assay}

3-(4, 5-Dimethylthiazol-2-Yl)-2, 5-Diphenyltetrazolium Bromide (MTT) assay was performed to assess the cell viability. Briefly, 96 well plates were used to seed cells at a density of $1 \times 10^{\wedge} 4$ cells per $100 \mu \mathrm{l}$ of DMEM media, complemented with $10 \%$ heat-inactivated fetal bovine serum, penicillin $\mathrm{G}(0.05 \mathrm{mg} / \mathrm{ml})$, and streptomycin $(0.08 \mathrm{mg} / \mathrm{ml})$ and allowed to grow at $37^{\circ} \mathrm{C}$ for $24 \mathrm{~h}$. Then, the cells were added with different concentrations of free MTX and MTX SLNs, at a concentration of MTX ranging from $2 \mu \mathrm{g} / \mathrm{ml}$ to $100 \mu \mathrm{g} / \mathrm{ml}$. Subsequently, a longer incubation of $48 \mathrm{~h}$ and $72 \mathrm{~h}$ was used to ensure a high degree of killing. Blank SLNs and no cell treatment were taken as the control. After incubation and removal of the medium, $100 \mu \mathrm{l}$ of MTT solution in phosphate buffer $(5 \mathrm{mg} / \mathrm{ml})$ was added to each well of the plate. The plate was wrapped in aluminum foil and incubated for four and a half hours. After draining the plate, $100 \mu \mathrm{l}$ of isopropyl alcohol was added to the individual wells and each well was subjected to absorbance at $570 \mathrm{~nm}$ employing an EL $\times$ 800 microplate absorbance reader (Bio-Tek Instruments, Winooksi, VT) having reference wavelength of $630 \mathrm{~nm}$ [24]. The cell viability (\%) was calculated using the following equation:

$$
\begin{gathered}
\%(\text { viability })=\frac{\text { (optical density [OD]treat- OD blank }) * 100 \%}{(\text { OD control- OD blank })} \\
\% \text { cytotoxicity }=1-\% \text { (viability) }
\end{gathered}
$$

\section{In vivo pharmacokinetic study}

The animal testing was sanctioned by the School of Biotechnology, Animal Ethics Committee, KIIT University, Bhubaneswar, India. Male SD rats (200-250 g) were accommodated in Animal Maintenance Centre with unlimited availability of food for $7 \mathrm{~d}$. Nonetheless, before and during the experimentation process, the rats were permissible to drink only water. Two sample suspensions were prepared:

1) Free MTX was dispersed in freshly prepared double distilled water (Human equivalent dose: $2.5 \mathrm{mg}$ )

2) MTX SLNs was diluted with double-distilled water (Human equivalent dose: $2.5 \mathrm{mg}$ ).

Twelve SD rats were placed in four groups by random division. After dosing, blood samples $(600 \mu \mathrm{l})$ were obtained by retro-orbital venous plexus puncture under mild ether anesthesia and collected in heparinized tubes. Time points were as follows: $0 \mathrm{~h}, 1 \mathrm{~h}, 5 \mathrm{~h}, 12 \mathrm{~h}$, and $24 \mathrm{~h}$. The plasma obtained after centrifugation at 8,000 rpm for $10 \mathrm{~min}$ was straightaway separated. Until further studies, the plasma samples were stockpiled at $-20^{\circ} \mathrm{C}$. The plasma $(50 \mu \mathrm{l})$ was processed by taking it into $1.5 \mathrm{ml}$ capacity tubes. To these tubes, $0.1 \%$ formic acid ( $50 \mu \mathrm{l}$ ) was added as a modifier and later vortexed for $2 \mathrm{~min}$. These were further extracted with $1 \mathrm{ml}$ cold acetonitrile accompanied with agitation using a vortex mixer for $2 \mathrm{~min}$. It was later centrifuged at $14,000 \mathrm{rpm}$ for $10 \mathrm{~min}$. A mixture of methanol and $0.1 \%$ formic acid (9:1) was used as the mobile phase. Consequently, LC-MS-MS were performed on the $20 \mu \mathrm{l}$ aliquots of each supernatant which was having an ultraviolet-visible detector (AB Sciex API 3000). $\lambda \max 306 \mathrm{~nm}$ with flow output of $1 \mathrm{ml} / \mathrm{min}$ employed for the detection.

\section{Statistical analysis}

The results were stated as mean \pm standard deviation and tested using a student's $t$-test at the level of $p<0.05$.

\section{RESULTS AND DISCUSSION}

\section{Solubility of MTX in solid lipids}

In SLN formulation, the amount of drug being entrapped into solid lipid is a limiting factor. As per the data are shown in table 1, four different solid lipids were taken to perform a solubility study. Amongst them, GMS, showed higher solubility than Compritol, Precirol, and stearic acid due to the presence of two $\mathrm{OH}$ groups to incorporate MTX. Therefore GMS was taken further for preliminary optimization [25].

Table 1: Solubility study (Data represents mean $\pm \mathrm{SD}, n=3$ )

\begin{tabular}{lll}
\hline Lipids & Melting point $\left({ }^{\circ} \mathrm{C}\right)$ & Drug: lipid ratio (D: L) 1:20 \\
\hline GMS & $55-60$ & +++ \\
Stearic acid & $69-70$ & ++ \\
Compritol 888 ATO & $65-77$ & + \\
Precirol AT0 5 & $50-60$ & + \\
\hline
\end{tabular}

+Not clear, ++Turbid, +++Clear

\section{Preliminary screening of lipid, solubilizer and sonication time}

Solubility studies result showed that GMS exhibited a particle size and PDI of $290.32 \pm 4.98 \mathrm{~nm}$ (z-average) and 0.589 \pm 0.071 , respectively. The $\% \mathrm{EE}$ of $63.1 \pm 2.14$ was highest with GMS compared with the other three lipids. The low encapsulation efficiency may be attributed to the relatively lower solubility of MTX in lipids. MTX is 
easily expelled to the external aqueous phase during the process of lipid re-crystallization. GMS, which has two free $\mathrm{OH}$ groups in its structure and hence exhibits somewhat hydrophilic property, could entrap MTX in a reasonable quantity but still exhibited poor entrapment efficiency. Hence, GMS was selected as an optimized lipid. Further, to improve the encapsulation efficiency, two solubilizers, namely polyethylene glycol (PEG) 200 and polyethylene glycol (PEG) 400 were tried at $2 \% \mathrm{w} / \mathrm{w}, 3 \% \mathrm{w} / \mathrm{w}$ and $4 \% \mathrm{w} / \mathrm{w}$ (Batch no.2-7, table 2a). Also, as seen from Batch 1 and 6, the use of surfactant with solubilizer and PEG 200 resulted in a reduction in particle size and PDI as compared to the formulation without a solubilizer. Table 2a shows that size and PDI were lowest and considerable entrapment efficiency was achieved with PEG 200 at $3 \% \mathrm{w} / \mathrm{w}$ concentration. PEG minimizes the need for harsh solvents needed during micro-encapsulation. Various studies suggest that SLN formulations with a blend of surfactants display higher kinetic stability with a lower particle size as opposed to formulations prepared by the use of one surfactant [12]. Table 2a clearly shows that a combination of surfactant (tween 80 and Kolliphor HS 15) and a solubilizer (PEG 200) (Batch no. 10) showed the lowest size and PDI when compared to a single surfactant (tween 80) (Batch no. 1) or a single surfactant (tween 80) with a solubilizer (PEG 200) (Batch no. 6). Fall in size can be attributed to stabilizing effect of the second surfactant. This stabilizing effect could an outcome of a fall in surface tension, thereby causing particle wetting and size reduction. The usage of a combination of surfactants viz., tween 80 and Kolliphor HS 15 helped in rapidly covering the newly formed surfaces of the lipid during the sonication process and resulted in increased surface area and avoiding aggregation [25]. A blend of tween 80 and Kolliphor HS 15 (Batch no. 10) helped in achieving a higher \%EE of $98.7 \pm 1.55$. The reason being an increase in viscosity caused by the addition of Kolliphor HS 15, leading to lesser drug diffusion. Also, when sonication time was increased from 5 to $10 \mathrm{~min}$, size $(234.21 \pm 2.3 \mathrm{~nm}$ to $216.43 \pm 1.3 \mathrm{~nm})$ and PDI $(0.253 \pm 0.045$ to $0.243 \pm 0.054)$ was gradually decreased and $\% \mathrm{EE}(92.14 \pm 2.57$ to 94.34 \pm 2.63 ) was increased (Batch no. 12-14, table 2b). Consequently, when sonication time was increased up to $12 \mathrm{~min}$ (Batch no.15, table 2b) there was no further significant change in particle size, PDI and \%EE. This could be because the higher kinetic energy provided by the sonication process could not contribute to the lowering of size and PDI further since even the lipid center is already shaped with lower size and PDI. At higher rpm, the lipid matrix is cracked open and there is a probability of drug leaching out from the lipid matrix into the external phase [12]. Therefore, solubilizer $(3 \% \mathrm{w} / \mathrm{w})$ and sonication time $(10 \mathrm{~min})$ were established as fix levels for further trials.

Table 2a: Preliminary screening of solubilizer and a combination of surfactants (Data represents mean \pm SD, $n=3$ )

\begin{tabular}{|c|c|c|c|c|c|c|c|c|c|c|c|}
\hline \multirow[t]{2}{*}{ Batch no. } & 1 & 2 & 3 & 4 & 5 & 6 & 7 & 8 & 9 & 10 & 11 \\
\hline & \multicolumn{11}{|c|}{$\% w / w$} \\
\hline GMS & 1.5 & 1.5 & 1.5 & 1.5 & 1.5 & 1.5 & 1.5 & 1.5 & 1.5 & 1.5 & 1.5 \\
\hline PEG 400 & & 2 & 3 & 4 & & & & & & & \\
\hline PEG 200 & & & & & 2 & 3 & 4 & 3 & 3 & 3 & 3 \\
\hline Tween 80 & 1.5 & 1.5 & 1.5 & 1.5 & 1.5 & 1.5 & 1.5 & 1.5 & 1.5 & 1.5 & 1.5 \\
\hline Gelucire & & & & & & & & 1.5 & & & \\
\hline Cremophor RH40 & & & & & & & & & 1.5 & & \\
\hline Kolliphor HS 15 & & & & & & & & & & 1.5 & \\
\hline Cremophor EL & & & & & & & & & & & 1.5 \\
\hline Batch no. & 1 & 2 & 3 & 4 & 5 & 6 & 7 & 8 & 9 & 10 & 11 \\
\hline \multirow[t]{2}{*}{ Size $(\mathrm{nm})$} & 290.32 & 286.56 & 273.12 & 268.78 & 256.54 & 242.08 & 236.12 & 324.65 & 356.43 & 226.32 & 386.32 \\
\hline & \pm 4.98 & \pm 3.53 & \pm 2.32 & \pm 5.28 & \pm 3.08 & \pm 4.19 & \pm 3.99 & \pm 4.36 & \pm 6.28 & \pm 3.71 & \pm 5.01 \\
\hline \multirow[t]{2}{*}{ PDI } & 0.589 & $0.342 \pm 0.05$ & 0.322 & 0.343 & $0.358 \pm 0$ & $0.234 \pm 0$ & 0.243 & $0.431 \pm$ & $0.334 \pm$ & $0.243 \pm$ & $0.272 \pm 0$ \\
\hline & \pm 0.071 & 1 & \pm 0.098 & \pm 0.051 & 039 & .067 & \pm 0.056 & 0.063 & 0.032 & 0.025 & 018 \\
\hline \multirow[t]{2}{*}{$\% \mathrm{EE}$} & $63.1 \pm 2$ & $94.6 \pm 3.13$ & $92.1 \pm 2$ & $95.1 \pm 5$ & $93.65 \pm 4$. & $98.5 \pm 2$ & $95.2 \pm 2$ & $94.3 \pm 1$ & $96.2 \pm 3$ & $98.7 \pm 1$ & $91.3 \pm 1.1$ \\
\hline & 14 & & .63 & 35 & 7 & 54 & 57 & 56 & .33 & .55 & 9 \\
\hline
\end{tabular}

*Drug concentration was maintained constant $(0.08 \% \mathrm{w} / \mathrm{w})$ in all batches

Table 2b: Optimization of the sonication time of the batch screened in table 2a (Data represents mean \pm SD, $n=3$ )

\begin{tabular}{|c|c|c|c|c|}
\hline Optimization of sonication time & Batch no. 12 & Batch no. 13 & Batch no. 14 & Batch no. 15 \\
\hline Batch no. & 10 & 10 & 10 & 10 \\
\hline Sonication time (min) & 5 & 7 & 10 & 12 \\
\hline Batch no. & 12 & 13 & 14 & 15 \\
\hline Size $(\mathrm{nm})$ & $234.21 \pm 2.3 \mathrm{~nm}$ & $226.54 \pm 1.3 \mathrm{~nm}$ & $216.43 \pm 3.5 \mathrm{~nm}$ & $214.56 \pm 4.5 \mathrm{~nm}$ \\
\hline PDI & $0.253 \pm 0.045$ & $0.234 \pm 0.064$ & $0.243 \pm 0.054$ & $0.22 \pm 0.011$ \\
\hline$\% \mathrm{EE}$ & $92.14 \pm 2.57$ & $93.27 \pm 3.32$ & $94.34 \pm 2.63$ & $95.13 \pm 1.12$ \\
\hline
\end{tabular}

*Drug concentration was maintained constant $(0.08 \% \mathrm{w} / \mathrm{w})$ in all batches

Table 3: Design matrix for factor screening as per $3^{2}$ factorial design along with actual and coded values for the CMAs

\begin{tabular}{lll}
\hline Types of variables Independent variables (CPP) & & Levels (Coded) \\
\cline { 2 - 3 } & Low & Medium \\
\hline X1= Concentration of lipid $(\% \mathrm{w} / \mathrm{w})$ & -1 & 0 \\
X2= Concentration of surfactant $(\% \mathrm{w} / \mathrm{w})$ & -1 & 0 \\
Dependent variables (CQA) & & +1 \\
Y1= Particle size(nm & & \\
Y2= PDI & & \\
Y3= $\%$ EE & Low level $(-1)$ & Medium level $(0)$ \\
Levels of factor studied & 1.5 & 2 \\
Factors & 1.5 & 2 \\
Concentration of lipid $(\% \mathrm{w} / \mathrm{w})$ & 3 \\
Concentration of surfactant $(\% \mathrm{w} / \mathrm{w})$ & & 3 \\
\hline
\end{tabular}




\section{$3^{2}$ factorial design}

$3^{2}$ factorial design helped in analyzing the effect of CPP on CQA (table 3). Eleven experimental runs were led and outcomes were shown in table 4. ANOVA of Size, PDI, and \% EE was presented in table 5. The models that were found to fit the best for the depend ent variables were linear, Quadratic, and 2FI, respectively. The data was in alignment with the 3D response surface plot (fig. 1). Table 5 specified that the consequence of CPP on CQA is noteworthy (significance value<0.05).

Table 4: Size, PDI and \% EE of factorial runs and validation batches (Data represents mean $\pm S D, n=3$ )

\begin{tabular}{|c|c|c|c|c|c|}
\hline Run & $\begin{array}{l}\text { X1 Concentration of lipid } \\
(\% \mathrm{w} / \mathrm{w})\end{array}$ & $\begin{array}{l}\text { X2 Concentration of surfactant } \\
(\% w / w)\end{array}$ & Y1 & Y2 & Y3 \\
\hline 1 & 1.5 & 1.5 & $313.4 \pm 5.29$ & $0.459 \pm 0.032$ & $67.8 \pm 2.13$ \\
\hline 2 & 1.5 & 2 & $351.8 \pm 4.89$ & $0.238 \pm 0.022$ & $81.2 \pm 1.89$ \\
\hline 3 & 1.5 & 3 & $64.3 \pm 3.43$ & $0.375 \pm 0.039$ & $88.4 \pm 1.11$ \\
\hline 4 & 2 & 1.5 & $407.2 \pm 6.55$ & $0.433 \pm 0.051$ & $80.64 \pm 2.56$ \\
\hline 5 & 2 & 2 & $238 \pm 4.11$ & $0.67 \pm 0.029$ & $86.42 \pm 2.44$ \\
\hline 6 & 2 & 3 & $143.9 \pm 5.01$ & $0.28 \pm 0.043$ & $96.7 \pm 1.21$ \\
\hline 7 & 3 & 1.5 & $517.8 \pm 3.72$ & $0.428 \pm 0.036$ & $84.64 \pm 1.35$ \\
\hline 8 & 3 & 2 & $297.1 \pm 4.36$ & $0.212 \pm 0.047$ & $83.47 \pm 2.47$ \\
\hline 9 & 3 & 3 & $272.6 \pm 5.63$ & $0.317 \pm 0.036$ & $82.64 \pm 2.78$ \\
\hline 10 & 0.75 & 2.25 & $147.21 \pm 3.23$ & $0.281 \pm 0.042$ & $90.91 \pm 1.38$ \\
\hline 11 & 0.375 & 2.55 & $153.72 \pm 2.78$ & $0.290 \pm 0.031$ & $92.73 \pm 3.18$ \\
\hline
\end{tabular}

*Drug concentration was maintained constant $(0.08 \% \mathrm{w} / \mathrm{w})$ in all batches
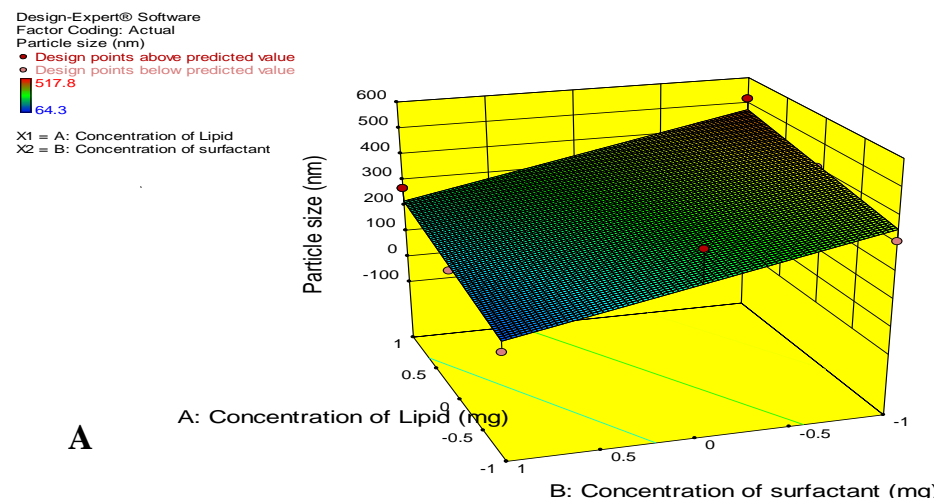

A A: Concentration of Lipid (mgng)

B: Concentration of surfactant $(\mathrm{mg})$

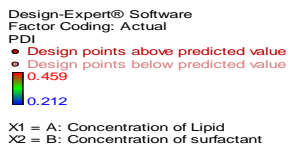

B
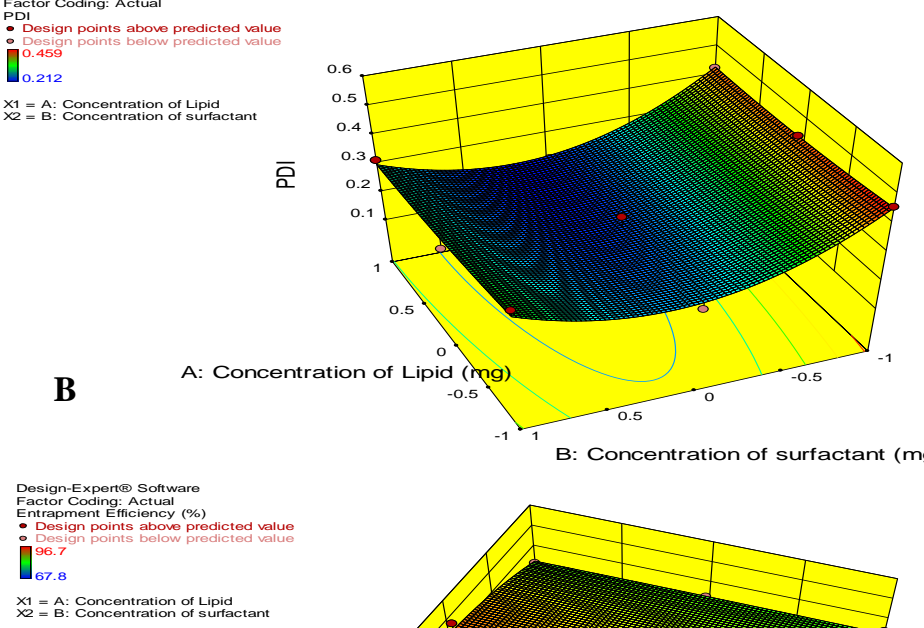

C

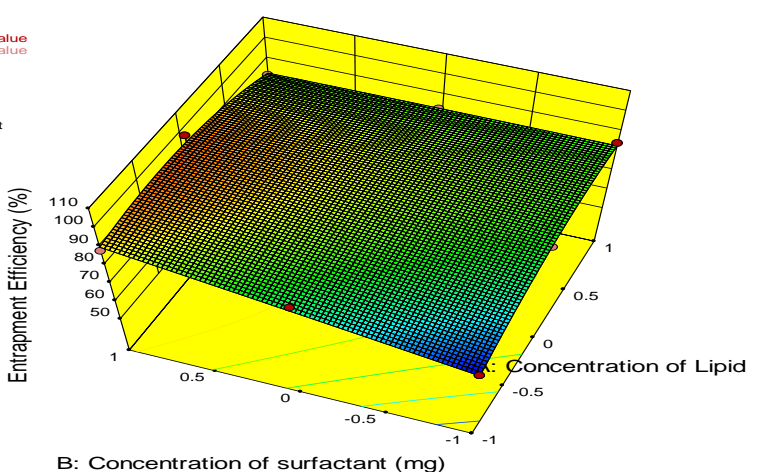

Fig. 1: 3D response surface plot of CQA; (A)-Size, (B)-PDI and (C)-\%EE 
Table 5: ANOVA of size, PDI, and \% EE

\begin{tabular}{|c|c|c|c|c|c|c|c|}
\hline Response & Source & $\begin{array}{l}\text { Sum of } \\
\text { squares }\end{array}$ & df & $\begin{array}{l}\text { Mean } \\
\text { square }\end{array}$ & $\begin{array}{l}\text { F } \\
\text { value }\end{array}$ & $\begin{array}{l}\text { p-value } \\
\text { prob }>F\end{array}$ & \\
\hline Particle & Model & $1.170 \mathrm{E}+005$ & 2 & 58522.08 & 12.33 & 0.0075 & significant \\
\hline \multirow{4}{*}{ size } & A-Concentration of Lipid & 21384.54 & 1 & 21384.54 & 4.51 & 0.0780 & \\
\hline & B-Concentration of surfactant & 95659.63 & 1 & 95659.63 & 20.15 & 0.0042 & \\
\hline & Residual & 28477.37 & 6 & 4746.23 & & & \\
\hline & Cor Total & $1.455 \mathrm{E}+005$ & 8 & & & & \\
\hline \multirow[t]{5}{*}{ PDI } & Model & 0.064 & 5 & 0.013 & 9.55 & 0.0462 & significant \\
\hline & A-Concentration of Lipid & $2.204 E-003$ & 1 & $2.204 E-003$ & 1.65 & 0.2889 & \\
\hline & B-Concentration of surfactant & 0.020 & 1 & 0.020 & 15.13 & 0.0301 & \\
\hline & Residual & 4.003E-003 & 3 & $1.334 \mathrm{E}-003$ & & & \\
\hline & Cor Total & 0.068 & 8 & & & & \\
\hline \multirow[t]{5}{*}{$\% \mathrm{EE}$} & Model & 443.83 & 5 & 88.77 & 10.68 & 0.0397 & significant \\
\hline & A-Concentration of Lipid & 29.70 & 1 & 29.70 & 3.57 & 0.1551 & \\
\hline & B-Concentration of surfactant & 200.22 & 1 & 200.22 & 24.09 & 0.0162 & \\
\hline & Residual & 24.93 & 3 & 8.31 & & & \\
\hline & Cor Total & 468.76 & 8 & & & & \\
\hline
\end{tabular}

\section{Data optimization and model validation}

The overlay plot (fig. 2) encompasses two areas viz., the yellow area, which signifies the space where you can get significant response values, and the grey area, which tells about the response values which will not meet the desired product quality. The optimized batch was selected based on overlay plot and desirability criteria. CPP viz. X1-Concentration of Lipid of $2 \%, \mathrm{X} 2-2.8 \% \mathrm{w} / \mathrm{w}$ of tween 80 and
Kolliphor HS 15 (1:1 ratio) and 3\% w/w PEG 200 and sonication time of $10 \mathrm{~min}$. The anticipated reading for the size, PDI, and \%EE was correspondingly $167.6 \mathrm{~nm}, 0.291$, and 93.02 as in the overlay plot, while the values for observed reading were as in table 6 (Batch no. 1).

Table 4 shows the formula of V1 and V2, whereas table 6 shows the observed versus predicted values of all responses and their degree of error for the validation batches.

Table 6: Observed versus the predicted value of CQA

\begin{tabular}{|c|c|c|c|c|c|c|c|c|c|}
\hline Run & Partic & & & PDI & & & \%EE & & \\
\hline & 0 & $\mathbf{P}$ & $\mathbf{R}$ & 0 & $\mathbf{P}$ & $\mathbf{R}$ & $\mathbf{0}$ & $\mathbf{P}$ & $\mathbf{R}$ \\
\hline 1 & 154.5 & 167.6 & -13.1 & 0.283 & 0.291 & -0.008 & 94.6 & 93.02 & 1.58 \\
\hline V1 & 147.2 & 165.0 & -17.8 & 0.281 & 0.283 & -0.002 & 90.91 & 91.6 & -0.69 \\
\hline $\mathrm{V} 2$ & 153.7 & 166.9 & -13.9 & 0.290 & 0.292 & -0.002 & 92.733 & 93.06 & -0.33 \\
\hline
\end{tabular}

(O- Observed, P- Predicted, R- Residual)

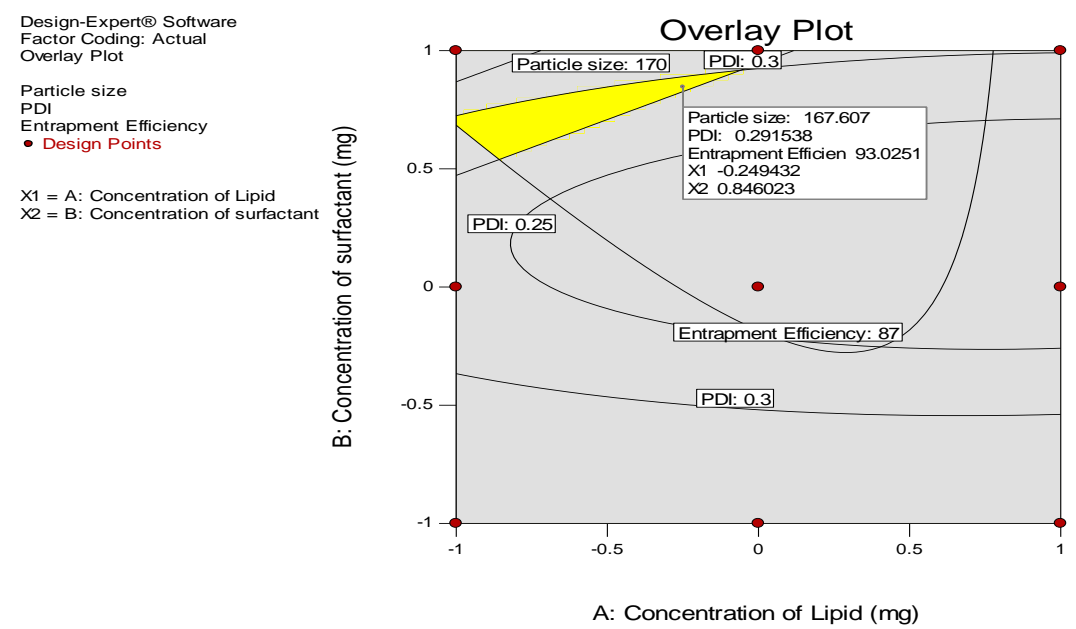

Fig. 2: Overlay plot showing a location of optimized MTX SLNs in design space

\section{Effect of concentration of lipid on particle size, PDI, and \%EE}

In the runs, the values of particle size, PDI, and \%EE ranged between 64.3 to $517.8 \mathrm{~nm}$ (z-average), 0.212 to 0.459 , and 67.8 to $96.7 \%$, respectively as shown in table 4 . It was observed that the concentration of lipids had a positive effect on particle size (Y1), PDI (Y2), and \%EE (Y3). It was attributed to the fact that increasing the lipid concentration increased the viscosity of the dispersed phase resulting in particle agglomeration and ultimately causing higher size, PDI, and decreased efficiency of homogenization. A higher extent of lipids offers bonus space for a drug molecule to embed in. Thus, leading to a rise in size and PDI alongside higher \%EE. Also, higher lipidic concentration resulted in higher entrapment efficiency because of reduced drug leaching from SLNs. From the result shown in table 4 , it was revealed that an increase in the concentration of lipid from $1.5 \% \mathrm{w} / \mathrm{w}$ to $2 \% \mathrm{w} / \mathrm{w}$ resulted in an increase in \%EE from $67.8 \% \pm 3.23$ to $86 \%$ and above in all the experimental runs.

\section{Effect of surfactant concentration on size, PDI, and \%EE}

As seen from table 4, a decrease in size and PDI and an increase in $\%$ EE was observed when the concentration of tween 80 and Kolliphor HS 15 (1:1) was gradually increased from $1 \%$ to $2 \% \mathrm{w} / \mathrm{w}$. Consequently, increasing concentration of tween 80 and Kolliphor 
HS 15 (1:1) from $2 \%$ to $3 \% \mathrm{w} / \mathrm{w}$, revealed decreased interfacial tension amongst the fatty acid and aqueous portion. This might regulate the clumping of lipid particles resulting in lower size and PDI. The lipid matrix was well stabilized by the steric hindrance created by the higher surfactant concentration, thereby avoiding aggregation [12].

\section{Characterization of optimized MTX SLN}

The average particle diameter of the improved MTX-SLNs suspension was found to be $147.6 \pm 4.1 \mathrm{~nm}$, PDI as $0.296 \pm 0.058$ (fig. 3). Small but narrow particle size is an indication of the consistent nature of the formulation. The zeta potential reading of $>30 \mathrm{mV}$ is an indication of a stable dispersion. As revealed in fig. 3 , the zeta potential of MTX SLNs was $-19 \pm 0.98 \mathrm{mV}$, revealing formulation was a physically steady system. The choice of lipid critically affects the $\% \mathrm{EE}$; hence trapping drugs in solid lipid becomes an interesting task in the formulation of SLNs. GMS played a dual role of an amphiphilic lipid and an emulsifying agent. Thus, forming a defective crystal framework to encapsulate MTX. The SLNs showed a \%EE of more than 90 (i.e. $94.61 \pm 2.7 \%$ ) due to GMS as a lipidic component. Assay value of $98.13 \pm 3.2 \%$ showed that more extent of MTX was existent in the SLN system [25].
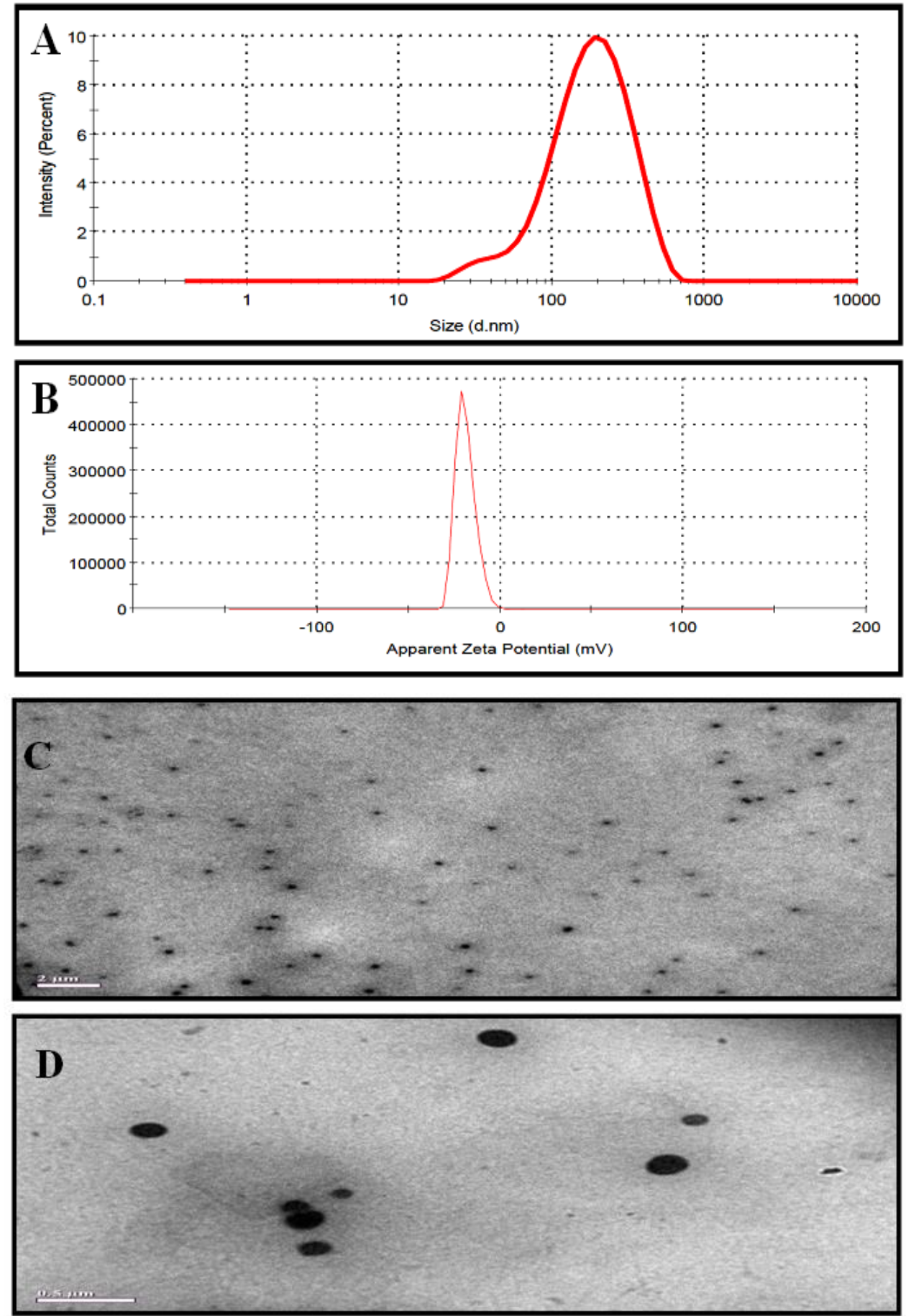

Fig. 3: Size distribution (A) and zeta potential (B) of MTX SLN measured by dynamic light scattering; transmission electron microscopy image of MTX SLN, the bar is $2 \mu \mathrm{m}$ (C); transmission electron microscopy image of MTX SLN showing the spherical shape of the nanoparticles, the bar is $0.5 \mu \mathrm{m}$ 


\section{TEM analysis}

The image acquired from the TEM (fig. 3) showed the optimized MTX SLNs with a spherical silhouette and a smooth outward appearance without agglomeration. They appeared in the range of $130 \mathrm{~nm}$ to $150 \mathrm{~nm}$. Dynamic light scattering (DLS) processes the hydrodynamic radius of any particle. Thus MTX SLNs appear to be of a lower size than by DLS. The TEM image showed the dry and shrunk configuration of MTX SLNs suspension [23].

\section{In vitro release studies}

The dynamic dialysis bag method was utilized to access in vitro drug-release performance of free MTX from MTX SLNs. Since Methotrexate has a low aqueous solubility, Hydrochloric acid $(\mathrm{HCl}$, $0.1 \mathrm{~N}$ ), and Phosphate-buffered saline (PBS; $0.1 \mathrm{mmol}, \mathrm{pH}$ 7.4) were used as the simulated gastric and intestinal fluid correspondingly. Fig. 4 illustrates the release dynamics of MTX from MTX SLNs and MTX suspension at pre-set time intervals. It was observed that the collective dissolution of MTX from the MTX suspension was quick, with $\sim 100 \%$ drug release observed in $2 \mathrm{~h}$, whereas MTXSLNs showed a primary spurt of $\sim 29 \%$ in $2 \mathrm{~h}$ and $95.59 \pm 0.918 \%$ in a constant fashion within $5 \mathrm{~h}$. Thus MTX SLNs showed prolonged-release characteristics over $5 \mathrm{~h}$. The release pattern from SLN is governed by lipid matrix as well as surfactant concentration. A burst release of MTX during the $1^{\text {st }} \mathrm{h}$ could be attributed to the amphiphilic nature of GMS, which helped in improving the solubility of MTX. The sustained release of the drug in the next few hours is because of the sluggish diffusion of the homogenously dispersed drug from the lipid matrix [26, 27].

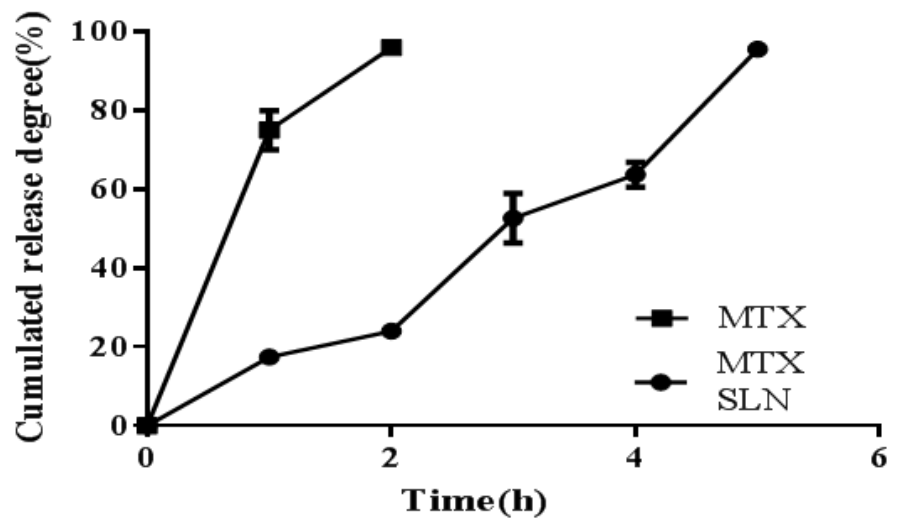

Fig. 4: In vitro release profile of MTX from MTX SLNs and free MTX suspension by a dialysis method in $0.1 \mathrm{~N}$ HCl for the $1^{\text {st }} \mathrm{h}$ followed by phosphate buffer (pH 7.4) for $4 \mathrm{~h}$ at $37^{\circ} \mathrm{C}$. Data shown are means \pm SEM $(n=3)$

Table 7: The appearance, solution color and mean particle size of the lyophilized powder of MTX-SLNs (Data represents mean \pm SD, $n=3$ )

\begin{tabular}{|c|c|c|c|c|}
\hline \multicolumn{2}{|c|}{ Numbers (lyophilized powder) } & \multirow{2}{*}{$\begin{array}{l}\text { Appearance } \\
\text { Flaxen, porous structure }\end{array}$} & Solution color & Particle size (nm), (mean \pm SD) \\
\hline MTX SLNs & & & Light yellow, translucent, clarified & $147.6 \pm 4.1 \mathrm{~nm}$ \\
\hline \multirow[t]{3}{*}{ Mannitol } & $3 \%$ & Milky white with a slightly yellow, & Milky, translucent, clarified & $167.3 \pm 3.3 \mathrm{~nm}$ \\
\hline & $5 \%$ & dense surface & & $202.5 \pm 1.8 \mathrm{~nm}$ \\
\hline & $7 \%$ & & & $216.3 \pm 1.6 \mathrm{~nm}$ \\
\hline \multirow[t]{3}{*}{ Lactose } & $3 \%$ & Milky white with a slightly yellow, & Milky, translucent, small amount & $202.75 \pm 4.21$ \\
\hline & $5 \%$ & sticky & of particles & $289.85 \pm 5.25$ \\
\hline & $7 \%$ & & & $305.33 \pm 8.14$ \\
\hline \multirow[t]{3}{*}{ Fructose } & $3 \%$ & Milky white with a slightly yellow, & Milky, translucent, small amount & $241.6 \pm 6.63$ \\
\hline & $5 \%$ & sticky & of particles & $247.7 \pm 8.39$ \\
\hline & $7 \%$ & & & $250.7 \pm 6.89$ \\
\hline \multirow[t]{3}{*}{ Dextrose } & $3 \%$ & Milky white with a slightly yellow, & Milky, translucent, small amount & $222.7 \pm 4.31$ \\
\hline & $5 \%$ & sticky & of particles & $253.1 \pm 4.92$ \\
\hline & $7 \%$ & & & $263.2 \pm 7.15$ \\
\hline
\end{tabular}

\section{Preparation of MTX-SLN lyophilized powder}

Freeze-drying improves the stability of SLN. The screening process for optimal cryoprotectant is defined in table 7. At 3\% mannitol $(\mathrm{w} / \mathrm{v})$ as a cryoprotectant, the lyophilized powder of the formulation presented the slightest change in particle size and led to a stable solution system. This dispersion containing $3 \%$ mannitol $(\mathrm{w} / \mathrm{v})$ was further mixed with neusilin $(7 \% \mathrm{w} / \mathrm{v})$ to improve the flow properties of the MTX SLN lyophilized powder.

\section{Characterization of freeze-dried powders}

\section{DSC analysis}

DSC analysis is a valuable tool to evaluate the crystallinity and melting point of a drug or polymer. The DSC curves of MTX SLNs, GMS, MTX, and physical blend (blank-SLNs: MTX), as in fig. 5. Thermograms for MTX SLNs as well as a physical mixture were alike, the reason being melting properties of SLNs were largely dependent on the fundamental lipid used. Only GMS showed a specific melting peak at $68.7^{\circ} \mathrm{C}$, which roughly corresponds to its melting point. A distinctive melting peak at $168.17{ }^{\circ} \mathrm{C}$ was observed for free MTX and it roughly corresponded to its melting point. Thus, the crystallinity of the drug was established [26]. The physical blend unveiled a melting peak at $137.23^{\circ} \mathrm{C}$, indicating the existence of free MTX. Interactions amongst MTX and excipients, especially the cryoprotectant, may have caused the shifting of the melting peak of the physical blend to a lower temperature [28, 29]. However, this shift was not considered a significant calling for a correction.

\section{Powder X-ray diffraction}

In fig. 6 diffraction pattern of MTX, MTX-SLNs, physical blend of MTX: blank-SLNs plus GMS is shown. Distinctive peaks present in MTX and physical blend endorses crystallinity of the MTX (fig. 6, red rectangles). However, the absence of the major crystalline peaks in the DSC diffraction pattern of MTX-SLNs, indicated that the entrapped MTX could be in a partial amorphous or disordered crystalline form [26]. This partial amorphous or disordered crystalline structure of MTX 
inside the SLNs helps in the complete but constant release from MTXSLNs $[28,29]$. The crystalline form of the drug in formulation impedes release because the enormous crystalline molecules face difficulty in diffusing through the tiny pores.

\section{FT-IR spectroscopy}

FT-IR spectroscopy is a rapid, economical, easy, plus non-destructive technique to access the stability of the drug in the formulation [26].
The FT-IR bands of MTX-SLNs, MTX, and a physical blend of blankSLNs: MTX is given in fig. 7. MTX on its own shows a distinctive absorption band around $3368.9 \mathrm{~cm}^{-1}$ as well as $3066.3 \mathrm{~cm}^{-1}$ relate to $\mathrm{N}-\mathrm{H}$ and $\mathrm{O}-\mathrm{H}$ stretching, whereas absorption bands nearby 1543.3 $\mathrm{cm}^{-1}$, as well as $1,464 \mathrm{~cm}-1$, might be ascribed to $\mathrm{N}-\mathrm{O}$ asymmetric stretching indicative of an amide bonding. These typical bands of MTX were also recognized in MTX-SLNs, which confirmed the identity and stability of MTX in SLNs.

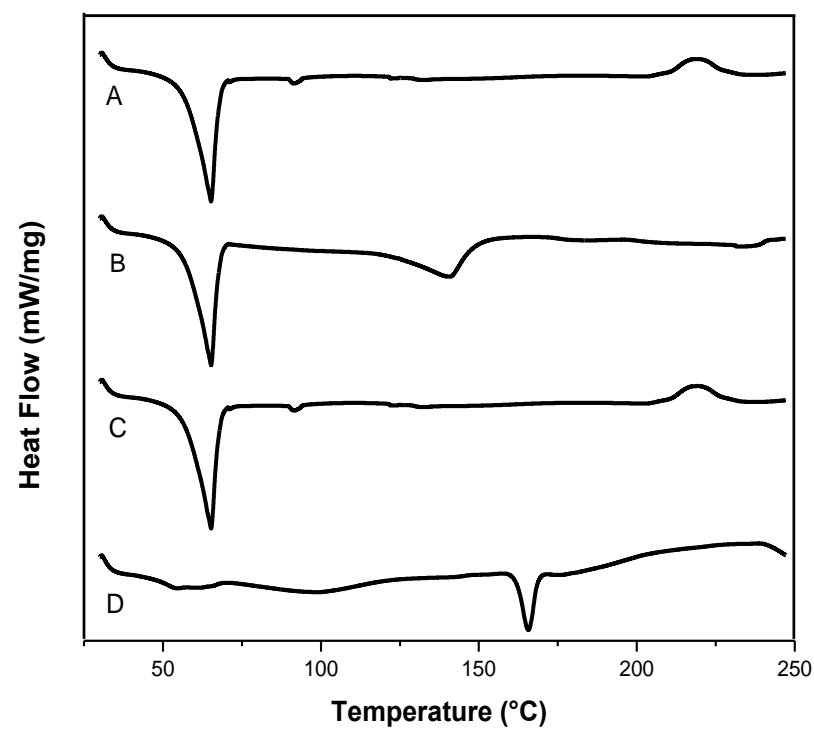

Fig. 5: DSC analysis of MTX SLNs (A), physical mixture of MTX and blank SLN (B), GMS(C), and MTX(D)

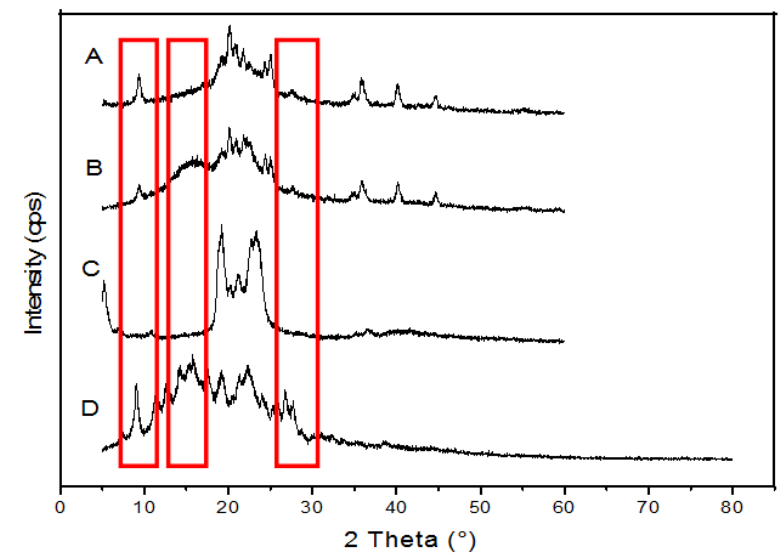

Fig. 6: X-ray diffraction patterns of MTX SLNs (A), physical mixture of MTX and blank SLN (B), GMS (C), and MTX (D)

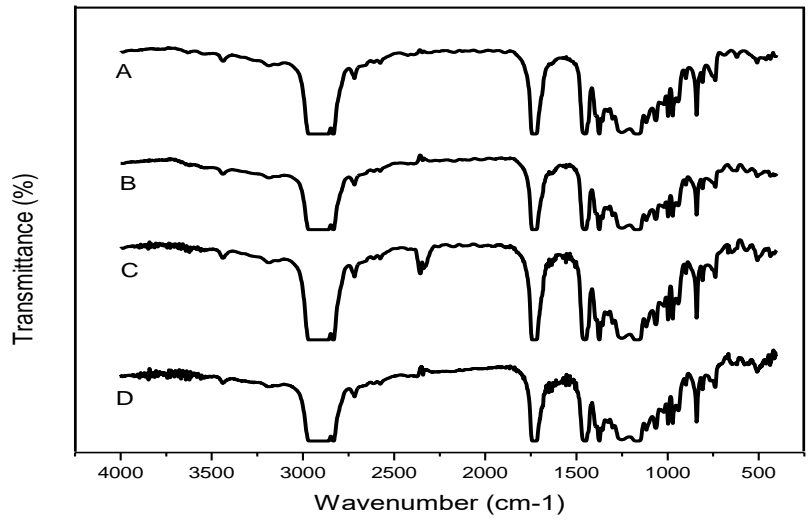

Fig. 7: FT-IR spectra of MTX SLNs (A), physical mixture of MTX and blank SLN (B), GMS(C), and MTX(D) 


\section{Cell evaluation}

\section{Cytotoxicity of MTX SLNs}

The cellular toxicity of MTX, blank-SLNs, and MTX-SLNs was studied using the HCT 116 cell line after 24-, 48-and 72-h exposure. The results of the study are shown in fig. 8. In HCT 116 cells, a noteworthy inhibition in growth was observed in the drugloaded SLNs compared with free MTX at the treated concentration range of $2-100 \mu \mathrm{g} / \mathrm{ml}$. Also, after $48-\mathrm{h}$ exposure at the same concentration used, MTX SLNs showed greater growth inhibition of HCT 116 cells as compared to control cells. There was no significant decrease in cell growth at $72 \mathrm{~h}$ exposure when compared to $48 \mathrm{~h}$ exposure to HCT 116 cells. Blank SLNs at the concentration of $100 \mu \mathrm{g} / \mathrm{ml}$ was used as a negative control. Blank SLNs was well tolerated and showed no cytotoxicity after 24-, 48and 72-h exposure at the concentration used and when compared with control cells $[30,31]$. In summary, MTX SLNs showed significant inhibition in HCT 116 cells as compared to free MTX, while blank SLNs were found to be non-cytotoxic, which further confirmed their safety in normal cells [32].
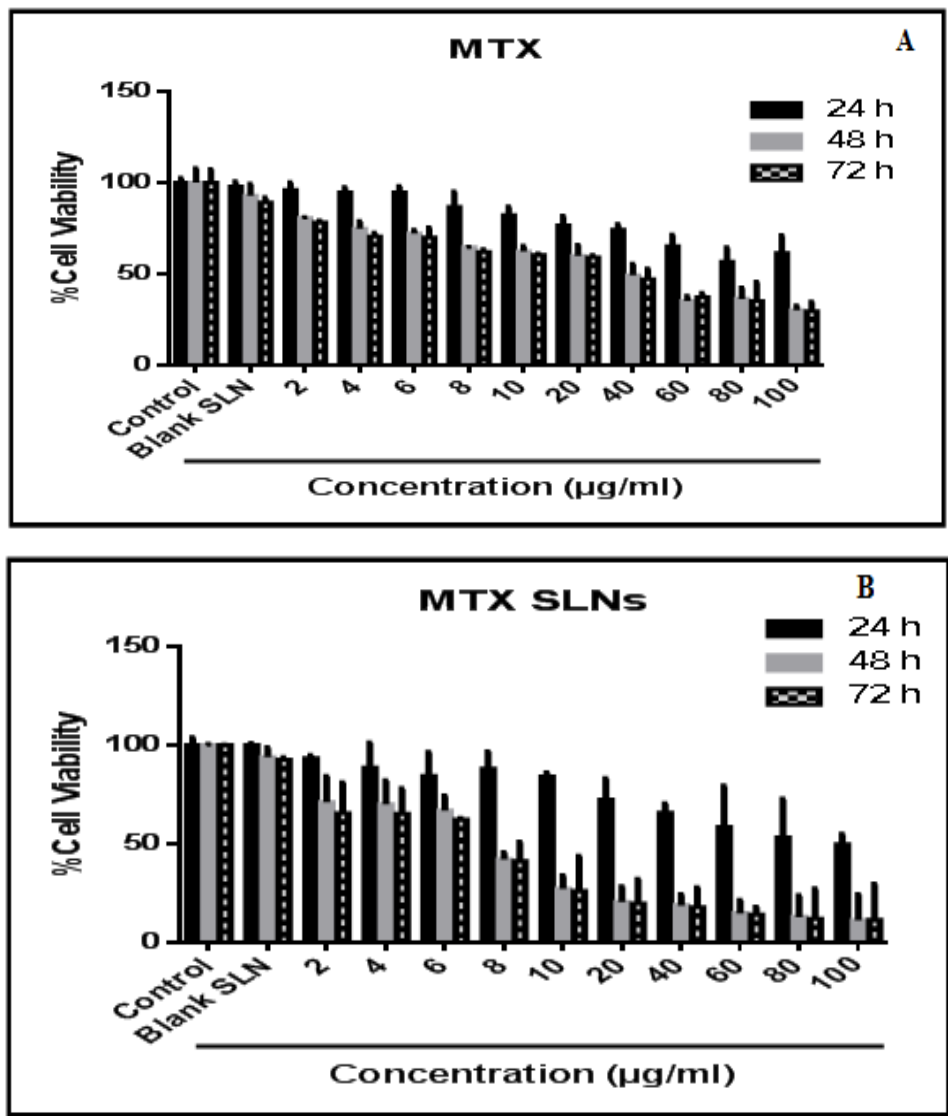

Fig. 8: Inhibition of proliferation following methotrexate (MTX) and methotrexate solid lipid nanoparticles (MTX SLNs) treatment. Cells $(10,000$ per well; HCT116), were treated with increasing concentrations $(2-100 \mu \mathrm{g} / \mathrm{ml})$ of MTX (A) or MTX SLNs (B) for 24-72 h. Results are expressed as \% cell survival of control and shown as mean \pm SEM $(n=3)$

\section{In vivo pharmacokinetic study}

An in vivo analysis to measure MTX after oral administration of MTX formulations was performed. The analysis was carried out with a student's unpaired t-test with a significance level of 0.05 . From plasma concentration-time outlines of individuals, the peak concentration (Cmax) and time of peak concentration (Tmax) were acquired diametrically. The relative bioavailability (Fr) was considered with the help of subsequent formula: $\operatorname{Fr}(\%)=[$ AUC $0 \rightarrow \infty$ (MTX-SLNs) $/$ AUC $0 \rightarrow \infty$ (MTX solution) $] \times 100$ Oral pharmacokinetic factors of MTX SLNs and MTX suspension are enumerated in table 8. The mean plasma concentration-time profile in rats is revealed in fig. 9. MTX concentrations in plasma for rats fed with MTX-SLNs were significantly higher with respect to those treated with suspension MTX. The AUC $0 \rightarrow 24 \mathrm{~h}$, AUC $0 \rightarrow \infty$, Cmax, and Fr of MTXSLN formulation after oral administration were nearly 3.531-fold, 3.514 -fold $(\mathrm{P}<0.05), 11.270$-fold $(\mathrm{P}<0.05)$, and 3.51 -fold greater than MTX suspension, respectively. The results indicated that the absorption of MTX after oral administration was significantly higher than the MTX-SLNs. The plausible reason for the higher absorption could be better solubilization of the drug in SLN formulation. Also, the drug was protected from enzymatic degradation because of being embedded in the lipid matrix. This study reveals the use of SLNs for the effective delivery of MTX via the oral route [33].

Table 8: Pharmacokinetic parameters of MTX after oral administration of MTX suspension and MTX SLNs suspension ( $n=6)$

\begin{tabular}{llll}
\hline Parameters & Unit & MTX & MTX SLNs \\
\hline $\mathrm{t}_{1 / 2}$ & $\mathrm{~h}$ & 4.558 & 7.649 \\
$\mathrm{~T} \max$ & $\mathrm{h}$ & 5 & 1 \\
$\mathrm{C} \max$ & $\mathrm{ng} / \mathrm{ml}$ & 48 & 541 \\
AUC 0-t & $\mathrm{ng} / \mathrm{mlh}$ & 476 & 1681 \\
AUC 0-inf_obs & $\mathrm{ng} / \mathrm{mlh}$ & 494 & 1736 \\
\hline
\end{tabular}




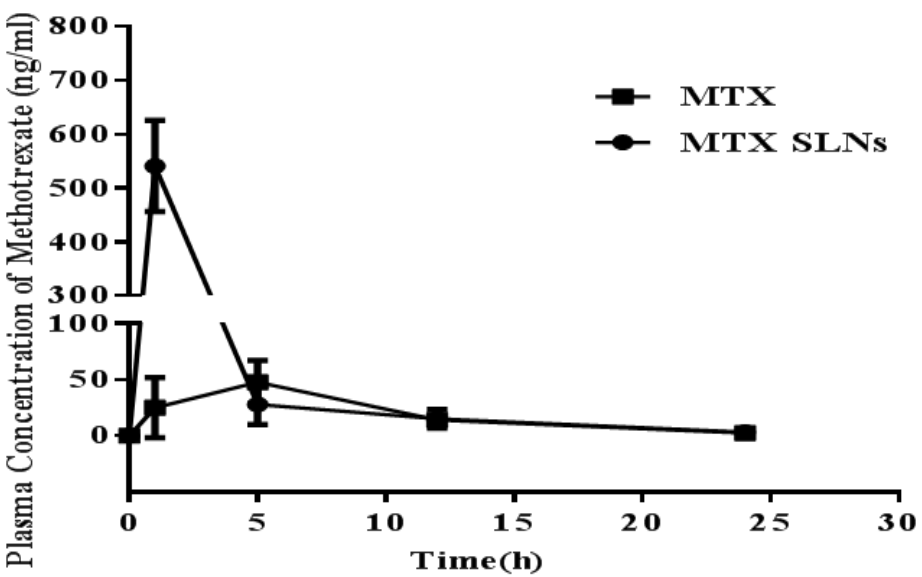

Fig. 9: In vivo bioavailability of native methotrexate (MTX) and nanoparticulate methotrexate (MTX SLNs). The rats were divided into two groups $(\mathrm{n}=6)$. An equivalent concentration of native methotrexate and nanoparticulate methotrexate $(0.26 \mathrm{mg} / \mathrm{kg}) \mathrm{was}$ given to group 1 and group 2 mice, respectively. Native methotrexate and nanoparticulate methotrexate were administered orally and blood was collected at different time intervals. Serum was separated and the concentration of methotrexate was determined by LC-MS-MS analysis. Results are expressed as mean \pm SEM $(n=3)$

\section{CONCLUSION}

In the current research, the novel carrier in the form of solid lipid nanoparticles was developed using the $\mathrm{QbD}$ approach for the effective delivery of Methotrexate. The nanoparticles were formulated using melt emulsification and ultrasonication technique. The distinct effects of critical process parameters on critical quality attributes were assessed using $3^{2}$ factorial designs to achieve the desired product quality. An optimized formulation for Methotrexate solid lipid nanoparticles was acquired from the overlay plot. \%EE of more than $90 \%$ in solid lipid nanoparticles indicated higher incorporation of methotrexate. Due to the lipidic nature of Methotrexate solid lipid nanoparticles, it showed higher drug diffusion in comparison to drug solution having the crystalline form of the drug. Differential scanning calorimetry and X-ray diffraction data additionally confirmed that methotrexate had lost its characteristic crystalline nature. Thus it could be concluded that the $\mathrm{QbD}$ could be successfully applied for the development of solid lipid nanoparticles with better quality attributes. The MTT cell viability assay using a human colon carcinoma cell line (HCT 116) demonstrated that the Methotrexate solid lipid nanoparticles used in this study showed significantly higher cytotoxicity than free MTX. A pharmacokinetic study carried out in male SD rats showed that Methotrexate solid lipid nanoparticles displayed a substantial improvement in the relative bioavailability in comparison to Methotrexate suspension after administration through the oral route. This work demonstrated that solid lipid nanoparticles offer a promising oral delivery system for increasing the bioavailability of Methotrexate.

\section{ACKNOWLEDGMENT}

We are grateful to $\mathrm{M} / \mathrm{s}$ Cipla Ltd, India, for generously providing Methotrexate and M/s BASF, Mannheim, Germany for providing Kolliphor HS15. This work was supported by Biotechnology Ignition Grant (BIG), BIRAC, Department of Biotechnology, Government of India, Project BIRAC/KIIT0030/BIG-05/14.

\section{FUNDING}

This work was supported by Biotechnology Ignition Grant (BIG), BIRAC, Department of Biotechnology, Government of India, Project BIRAC/KIIT0030/BIG-05/14.

\section{AUTHORS CONTRIBUTIONS}

Chaitali Surve and Ruchi Singh performed the synthesis of the methotrexate solid lipid nanoparticles, their characterization, and data analysis. Chaitali Surve and Ananya Banerjee designed and performed all the cell evaluations. Srinivas Patnaik designed the in vitro/in vivo experiments and data analysis. Supriya Shidhaye and
Chaitali Surve were responsible for designing the nanostructures. Chaitali Surve was responsible for writing the manuscript.

\section{CONFLICTS OF INTERESTS}

The authors declare no conflict of interest.

\section{REFERENCES}

1. Yoon SA, Choi JR, Kim JO, Shin JY, Zhang X, Kang JH. Influence of reduced folate carrier and dihydrofolate reductase genes on methotrexate-induced cytotoxicity. Cancer Res Treat 2010;42:163.

2. Khan ZA, Tripathi R, Mishra B. Methotrexate: a detailed review on drug delivery and clinical aspects. Expert Opin Drug Delivery 2012;9:151-69.

3. Kasim NA, Whitehouse M, Ramachandran C, Bermejo M, Lennernas $\mathrm{H}$, Hussain AS, et al. Molecular properties of WHO essential drugs and provisional biopharmaceutical classification. Mol Pharm 2004;1:85-96.

4. Chen YH, Tsai CY, Huang PY, Chang MY, Cheng PC, Chou CH, et al. Methotrexate conjugated to gold nanoparticles inhibits tumor growth in a syngeneic lung tumor model. Mol Pharm 2007;4:713-22.

5. Nogueira DR, Tavano L, Mitjans M, Perez L, Infante MR, Vinardell MP. In vitro antitumor activity of methotrexate via $\mathrm{pH}$-sensitive chitosan nanoparticles. Biomaterials 2013;34:2758-72.

6. Thomas TP, Huang B, Choi SK, Silpe JE, Kotlyar A, Desai AM, et al. Polyvalent dendrimer-methotrexate as a folate receptor-targeted cancer therapeutic. Mol Pharm 2012;9:2669-76.

7. Liang LS, Jackson J, Min W, Risovic V, Wasan KM, Burt HM. Methotrexate loaded poly(L-Lactic Acid) microspheres for intra-articular delivery of methotrexate to the joint. J Pharm Sci 2004;93:943-56

8. Smal MA, Dong Z, Cheung HTA, Asano Y, Escoffier L, Costello M, et al. Activation and cytotoxicity of 2- $\alpha$-aminoacyl prodrugs of methotrexate. Biochem Pharmacol 1995;49:567-74.

9. Kang H, Kim JD, Han SH, Chang IS. Self-aggregates of poly(2hydroxyethyl aspartamide) copolymers loaded with methotrexate by physical and chemical entrapments. J Controlled Release 2002;81:135-44.

10. Baek JS, Cho CW. Controlled release and reversal of multidrug resistance by co-encapsulation of paclitaxel and verapamil in solid lipid nanoparticles. Int J Pharm 2015;478:617-24.

11. Wilczewska AZ, Niemirowicz $\mathrm{K}$, Markiewicz $\mathrm{KH}$, Car $\mathrm{H}$. Nanoparticles as drug delivery systems. Pharmacol Reports 2012;64:1020-37. 
12. Mader K, Mehnert W. Solid lipid nanoparticles: production, characterization and applications. Adv Drug Delivery Rev 2001;47:165-96.

13. No Title, ICH Q9, June 2006 US food drug adm guid ind q9 qual risk manag. Available from: http//www.ich.org/ fileadmin/Public_Web_Site/ICH_Products/Guidelines/Quality/ Q8_R 1/Step4/Q8_R2_Guideline.pdf. [Last accessed on 05 May 2021]

14. No Title, ICH Q8 (R2), August 2009 Pharm Dev. Available from: http//www.fda.gov/downloads/Drugs/./Guidances/ucm0735 11.pdf. [Last accessed on 05 May 2021]

15. No Title, Wechsler J, 2008 FDA Propos Flex Overs Qual Syst Pharm Technol. Available from: http//www.pharmtech.com/ node/227632?rel=canonical. [Last accessed on 05 May 2021]

16. Li H, Zhao X, Ma Y, Zhai G, Li L, Lou H. Enhancement of gastrointestinal absorption of quercetin by solid lipid nanoparticles. J Controlled Release 2009;133:238-44.

17. Wang J, Zhu R, Sun X, Zhu Y, Liu H, Wang SL. Intracellular uptake of etoposide-loaded solid lipid nanoparticles induces an enhancing inhibitory effect on gastric cancer through the mitochondriamediated apoptosis pathway. Int J Nanomed 2014;9:3987-98.

18. Shah B, Khunt D, Bhatt H, Misra M, Padh H. Application of quality by design approach for intranasal delivery of rivastigmine loaded solid lipid nanoparticles: effect on formulation and characterization parameters. Eur J Pharm Sci 2015;78:54-66.

19. Tuanwei L, Xiao L, Jilan W, Ping Z, Xiaoying H, Zhide Z, et al.Ag@ S-nitrosothiol core-shell nanoparticles for chemo and synergistic photothermal tumor-targeted therapy. J Materials Chem B 2020;8:5483-90.

20. Chen J, Huang L, Lai H, Lu C, Fang M, Zhang Q, et al. Methotrexate-loaded PEGylated chitosan nanoparticles: synthesis, characterization, and in vitro and in vivo antitumoral activity. Mol Pharm 2014;11:2213-23.

21. Ji P, Yu T, Liu Y, Jiang J, Xu J, Zhao Y, et al. Naringenin-loaded solid lipid nanoparticles: Preparation, controlled delivery, cellular uptake, and pulmonary pharmacokinetics. Drug Des Dev Ther 2016;10:911-25.

22. Kumar A, Pandit $V$, Nagaich $U$. Therapeutic evaluation of chemically synthesized copper nanoparticles to promote full-thickness excisional wound healing. Int J Appl Pharm 2020;12:136-42.
23. Patel M, Patel NV, Patel TB. Design and development of rilpivirine nanoparticle-containing chitosan using ionic gelation method for HIV infections. Int J Pharm Pharm Sci 2020;12:113-8.

24. Gandamalla D, Iingabathula H, Yellu NR. Cytotoxicity evaluation of titanium and zinc oxide nanoparticles on human cell lines. Int J Pharm Pharm Sci 2017;9:240-6.

25. Abdelmonem R, El-nabarawi MA, Attia AM, Teaimaa M. Ocular delivery of natamycin solid lipid nanoparticle loaded mucoadhesive gel: formulation, characterization and in vivo study. Int J Appl Pharm 2020;12:173-80.

26. Gardouh AR, Gad S, Ghonaim HM, Ghorab MM. Design and characterization of glyceryl monostearate solid lipid nanoparticles prepared by high shear homogenization. J Pharm Res Int 2013;3:326-46.

27. Jamil l, Jan SU, Gul R. Formulation of microemulsion based gel of salbutamol sulphate and it's in vitro studies. Int J Curr Pharm Sci 2020;12:102-7.

28. Liu J, Gong T, Wang C, Zhong Z, Zhang Z. Solid lipid nanoparticles loaded with insulin by sodium cholatephosphatidylcholine-based mixed micelles: preparation and characterization. Int J Pharm 2007;340:153-62.

29. Zhang Y, Zhuo R. Synthesis and drug release behavior of poly (trimethylene carbonate)-poly (ethylene glycol)-poly (trimethylene carbonate) nanoparticles. Biomaterials 2005;26:2089-94.

30. Jingou J, Shilei H, Weiqi L, Danjun W, Tengfei W, Yi X. Preparation, characterization of hydrophilic and hydrophobic drug in combine loaded chitosan/cyclodextrin nanoparticles and in vitro release study. Colloids Surf B 2010;83:103-7.

31. Lou H, Gao L, Wei X, Zhang Z, Zheng D, Zhang D, et al. Oridonin nanosuspension enhances anti-tumor efficacy in SMMC-7721 cells and H22 tumor-bearing mice. Colloids Surf B 2011;87:319-25.

32. Ghosh S, More P, Derle A, Kitture R, Kale T, Gorain M, et al. Diosgenin functionalized iron oxide nanoparticles as novel nanomaterial against breast cancer. J Nanosci Nanotechnol 2015;15:9464-72.

33. Zhao Y, Guo Y, Li R, Wang T, Han M, Zhu C, et al. Methotrexate nanoparticles prepared with codendrimer from polyamidoamine (PAMAM) and oligoethylene glycols (OEG) dendrons: antitumor efficacy in vitro and in vivo. Sci Rep 2016;6:28983. 